\title{
Orthodontic intrusion of periodontally-compromised maxillary incisors: 3-dimensional finite element method analysis
}

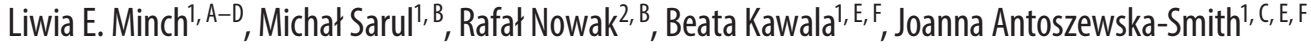 \\ ${ }^{1}$ Department of Dentofacial Orthopedics and Orthodontics, Wroclaw Medical University, Poland \\ 2 Department of Maxillofacial Surgery, Wroclaw Medical University, Poland \\ A - research concept and design; B - collection and/or assembly of data; C - data analysis and interpretation; \\ $D$ - writing the article; $E$ - critical revision of the article; $F$ - final approval of article
}

\author{
Address for correspondence \\ Liwia Minch \\ E-mail: liwiaminch@tlen.pl \\ Funding sources \\ National Science Center grant \\ no. NN518 382537

\section{Conflict of interest} \\ None declared

\section{Acknowledgements} \\ The authors would like to thank the National Science \\ Center for their financial support of this research.
}

Received on July 14, 2015

Revised on November 13, 2015

Accepted on January 12, 2016
DOI

10.17219/acem/61349

\section{Copyright}

Copyright by Author(s)

This is an article distributed under the terms of the

Creative Commons Attribution Non-Commercial License

(http://creativecommons.org/licenses/by-nc-nd/4.0/)

\begin{abstract}
Background. Loading of the compromised periodontium with orthodontic forces produces different results than those achieved in patients with healthy periodontal support. Determining the force value at a level preventing further deterioration of the patient's periodontal status, thus delivering the most precisely individualized "dose" of loading, seems to be crucial for the successful intrusion of teeth with reduced periodontal support.
\end{abstract}

Objectives. The aim of the study was to determine the range of force values efficiently intruding maxillary incisors without further compromising the initially-impaired periodontal status. Finite element analysis (FEA), allowing estimation of the stress and strain distribution, was the method of choice.

Material and methods. The CT scans of a periodontally-compromised patient were segmented using InVesalius software. A model - based on NURBS surfaces - was adjusted to the CT scans in order to obtain both smooth and natural curvatures of each model segment. All relevant tissues were modeled as separate volumes. The geometric model was discretized in order to create a numerical model for applying Ansys software (v. 15.07) and using APDL. The central incisors were loaded with external intrusive forces, ranging from 0.1 to $0.4 \mathrm{~N}$.

Results. The simulation, performed iteratively, showed that even the lowest force value - $0.1 \mathrm{~N}$ - causes stress changes in the alveolus and on the root surfaces, with a tendency of stress increasing towards the bottom of the alveolus and root apex. It is also notable that during the application of forces of equal magnitude, the stress/strain distribution was significantly higher around tooth 21, which displayed the highest range of PDL reduction. Application of the same force level created a higher stress-strain response around tooth 21, and the characteristics were less homogenous.

Conclusions. A force value of $0.1 \mathrm{~N}$ applied in vivo might produce the most effective tooth intrusion and bone modeling which favors bone defect regeneration.

Key words: FEM, intrusion, PDL, bone defect, orthodontic forces 


\section{Introduction}

It is assumed that the development of bone defects and attachment loss caused by periodontal disease leads, in $30-50 \%$ of patients, to extrusion and proclination of the maxillary incisors, which is also called pathologic tooth migration. ${ }^{1}$ Flared maxillary front teeth significantly handicap smile aesthetics and chewing function, therefore they require loading with orthodontic intrusive forces, provided the periodontal disease is stabilized and controlled. In the era of intensive development of multidisciplinary treatment approaches, the application of orthodontic intrusion seems to be beneficial in such cases, provided that the periodontium condition is stabilized. However, despite original studies and quite numerous case reports present in the current literature, intrusion of periodontally compromised teeth remains a controversial movement. ${ }^{2-5}$ The intrusive movement is subjected to a large risk of failure, predominantly apical root resorption and reduction of the alveolar bone height. ${ }^{6,7}$ The occurrence and range of these failures depend on many issues, but periodontal status as well as force magnitude and direction are the major factors. Loading of the compromised periodontium with orthodontic forces produces different results than those achieved in patients with healthy periodontal support. Determining the force value at a level preventing further deterioration of the patient's periodontal status, thus delivering the most precisely individualized "dose" of loading, seems to be crucial for the successful intrusion of teeth with reduced periodontal support. However, such a protocol demands certain measurements, impossible to be taken in vivo, but requiring in vitro studies and laboratory or numerical techniques, not as yet discussed in the literature.

The aim of the study was to determine the range of force values efficiently intruding maxillary incisors without further compromising the initially-impaired periodontal status. Finite element analysis (FEA) of a model with reduced periodontium, allowing estimation of the stress and strain distribution, was the method of choice.

\section{Material and methods}

The CT scans of a periodontally-compromised patient were segmented using InVesalius software (Fig. 1) in order to create a geometric model of the maxilla. This model - based on NURBS (Non-Uniform Rational B-Spline) surfaces - was subsequently adjusted to the CT scans in order to obtain both smooth and natural curvatures of each model segment. All relevant tissues were modeled as separate volumes - cortical bone, spongeous bone, periodontal ligaments (PDL), dentin, enamel and pulp (Fig. 2). The geometric model was discretized in order to create a numerical model for applying Ansys software (v. 15.07) and using APDL (ANSYS Parametric Design Language). The PDL layers of average thickness $0.1 \mathrm{~mm}$ were meshed using hexagonal finite elements, whereas the other tissues like bone (spongeous bone and cortical plates) and teeth (enamel and dentin) were meshed using tetragonal finite elements.

The literature review together with our personal experience made it possible to select the most suitable mechanical properties of particular tissues. ${ }^{8-11}$ The values displaying the mechanical properties of these tissues are shown in Table 1. As per PDL - considered as a structure displaying strongly nonlinear stress and strain distribution - a hyper-elastic Noe-Hookean material model was proposed. The model was calculated using non-linear elastic PDL properties (Fig. 3). The nominal stress level corresponding to the applied load was below $0.01 \mathrm{MPa}$, so the region on the strain-stress response of the PDL material was nearly linear, which is shown in Fig. 4.

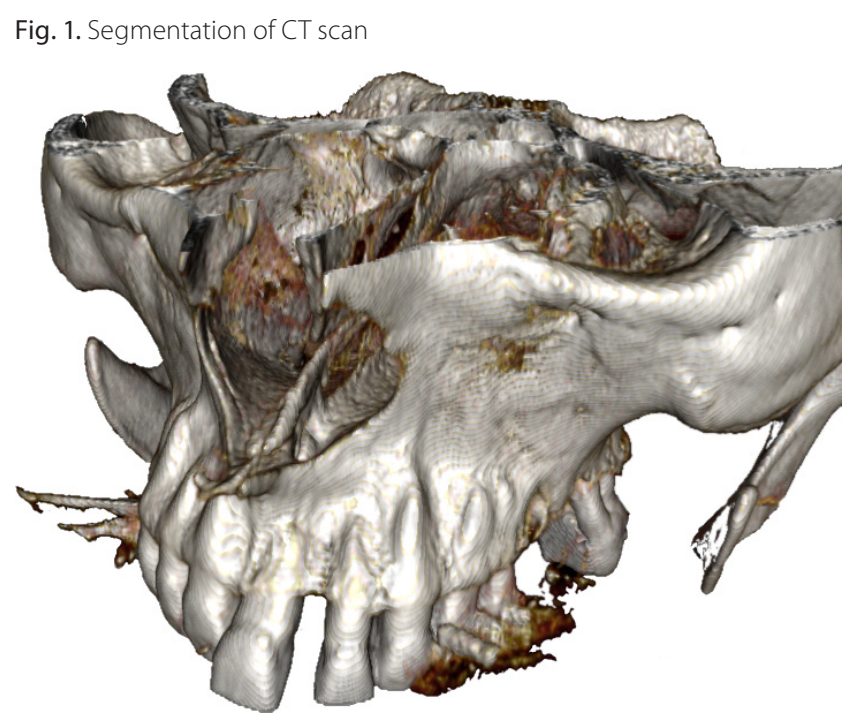

Fig. 2. Modeling of the cortical bone, spongeous bone, periodontal ligaments (PDL), dentin, enamel and pulp

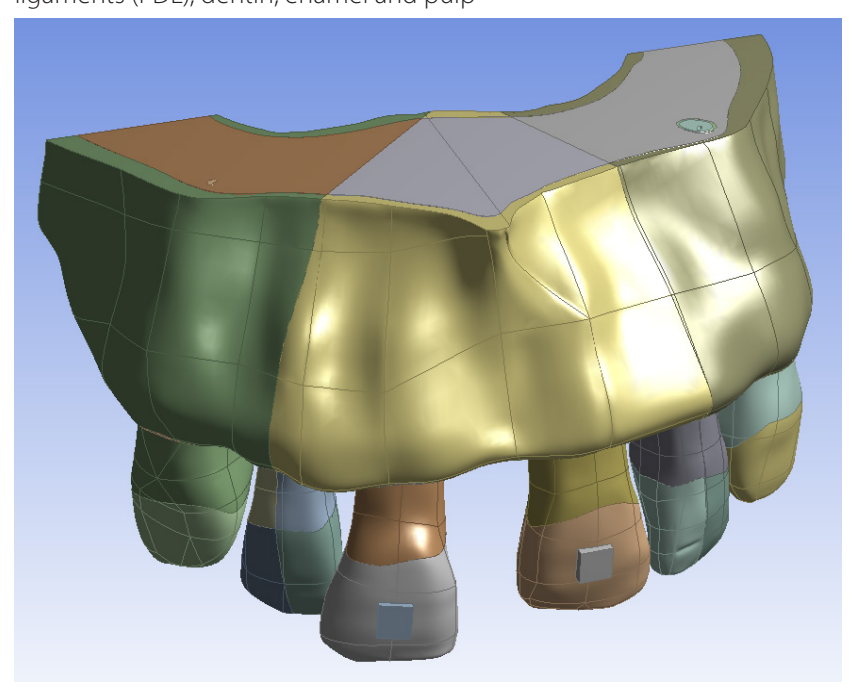


Fig. 3. PDL material properties with marked region of interest with respect to the nominal stress level in the PDL volume

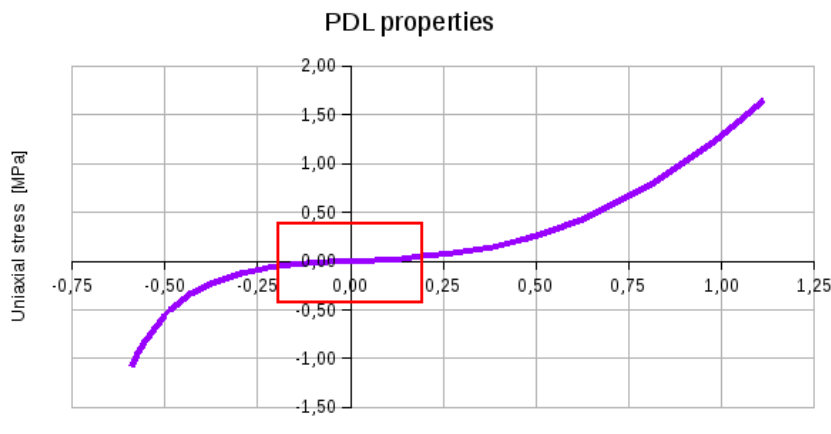

Strain

Fig. 4. Changes in the stress-strain distribution

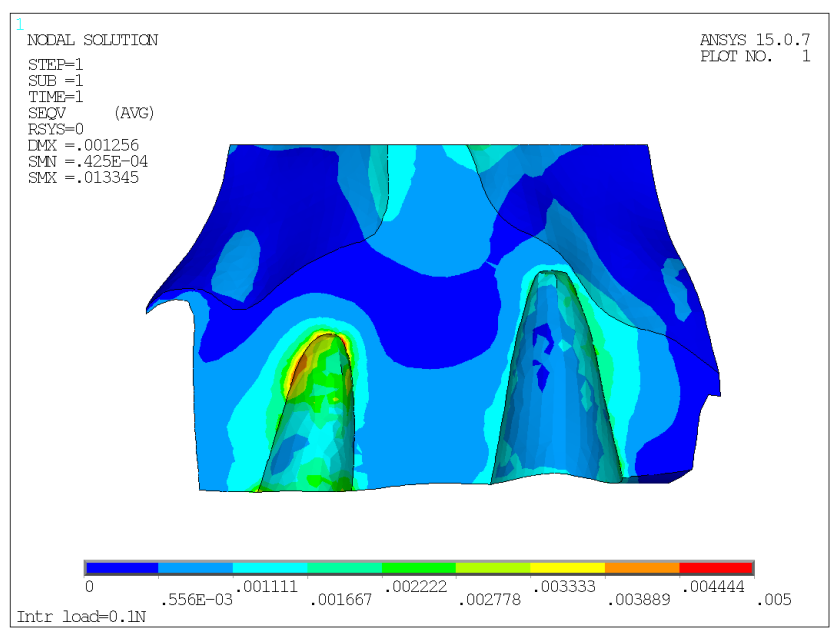

The central incisors were loaded with external intrusive forces, ranging from 0.1 to $0.4 \mathrm{~N}$ (with steps of $0.05 \mathrm{~N}$ ).

\section{Results}

The resulting data indisputably proved that a mechanical load, produced by an orthodontic fixed appliance, changes the mechanical properties of the bone tissues. The intrusive orthodontic force changes the stress-strain distribution (Fig. 4 and 5). The simulation, performed iteratively, showed that even the lowest force value, $0.1 \mathrm{~N}$, causes

Table 1. Material properties of evaluated tissues

\begin{tabular}{|l|c|c|}
\hline \multicolumn{1}{|c|}{ Material } & $\begin{array}{c}\text { Elasticity module } \\
{[\mathrm{MPa}]}\end{array}$ & $\begin{array}{c}\text { Poisson ratio } \\
{[-]}\end{array}$ \\
\hline Enamel & 85000 & 0.3 \\
\hline $\begin{array}{l}\text { Dentine } \\
\text { Cortical bone }\end{array}$ & 20000 & 0.3 \\
\hline $\begin{array}{l}\text { Spongeous } \\
\text { bone }\end{array}$ & 20000 & 0.3 \\
\hline
\end{tabular}

Fig. 5. Changes in the stress-strain distribution, lateral view

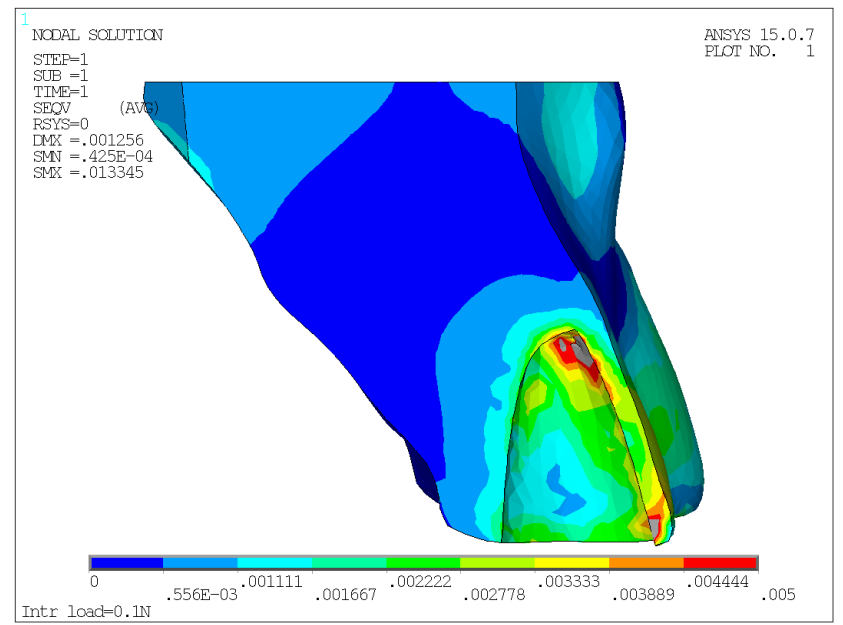

Fig. 6. Changes the stress-strain distribution, lateral view

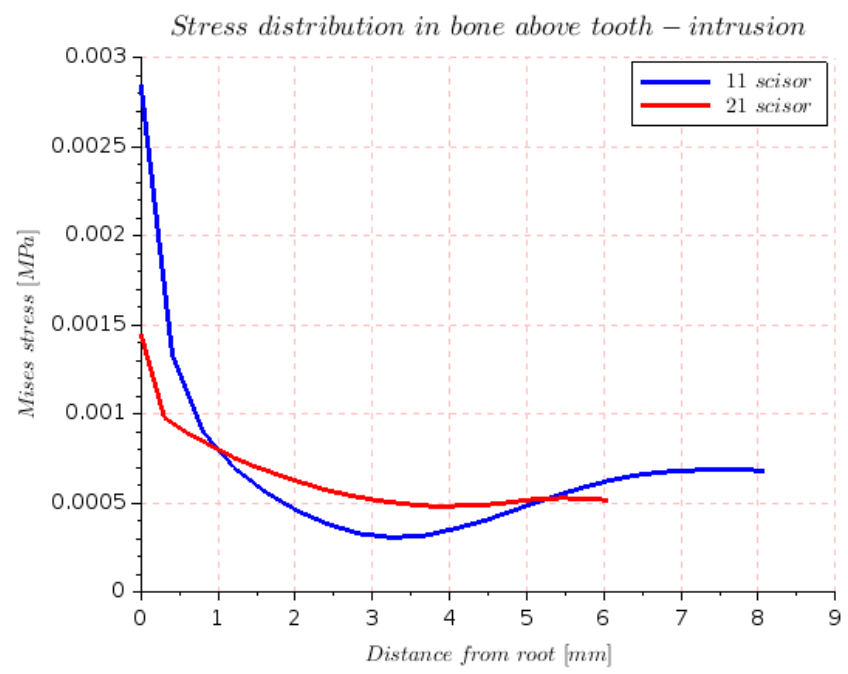

stress and strain changes in the alveolus and on the root surfaces, with a tendency of stress increasing towards the bottom of the alveolus and root apex. It is also notable that during the application of forces of equal magnitude, the stress/strain distribution was significantly higher around tooth 21, which displayed the highest range of PDL reduction. The periodontal ligaments supporting teeth 11 and 21 were weakened, however the bone defect adjacent to tooth 21 was more pronounced, hence application of the same force level created a higher stress-strain response around tooth 21, of the less homogenous characteristics (Fig. 6).

\section{Discussion}

Intrusive movement is laden with a high risk of multiple failures, e.g. root resorption, alveolar bone resorption or pulpal necrosis. ${ }^{7}$ Many aspects may contribute to the occurrence of such failures - general factors, e.g. genetic and systematic disorders or gender, as well as local factors 
such as orthodontic force direction, its magnitude and the duration of loading. ${ }^{12-14}$ Since these failures may be of iatrogenic origin, minimizing the risk of their occurrence should be of major concern to clinicians.

Moreover, intrusion of maxillary incisors that have migrated pathologically due to periodontitis is still controversial. ${ }^{15}$ Case reports available in the literature and a limited number of original studies show the positive influence of intrusion on periodontal tissues. ${ }^{2,3,5,16,17}$

Regardless of the direction of the tooth movement, evaluation of the periodontium remodeling influenced by orthodontic forces is impossible in vivo, which is why all of the results reported in the literature follow in vitro studies. Reviewing the literature reveals many measurement methods, e.g. the photo-elastic technique, laser holography and optomechanical set-up. ${ }^{18-20}$ However, each of these methods has some limitations; the finite element method (FEM) seems to be the most suitable, especially in a new millennium: the era of intensive development of different digital analysis techniques.

Since the highest resemblance of in vivo conditions in the generated model is of the utmost importance, we used CT scans of a patient to create a fully individualized FEM model of both structures, the jaw bones and teeth. In the literature, one may find papers reporting manual modeling of the particular elements, especially the teeth. ${ }^{21,22}$ However, the root shape is a very individual and unique feature and determines tooth behavior during intrusion, which was supported by studies of Levander and Malmgen. ${ }^{23}$ That is why individualization achieved due to using the patient's own model seems to be the most suitable. ${ }^{24}$

Moreover, in the present study, during modeling of the bony tissues, the cortical and spongeous bone were distinguished, as well as the dental structures: enamel, dentine and pulp. Even small differences in the anatomical changes affect the behavior of the studied parameters. Therefore it is important to customize the model. ${ }^{25}$ Since the PDL were a particular structure, they were given elastic and nonlinear features. It has been proven that bone remodeling is strongly related to PDL characteristics. ${ }^{26,27}$ Alveolar bone remodeling influenced by orthodontic forces differs from remodeling influenced by external loads with forces on the other bones. Orthopedic surgeons believe that mechanical forces causing compression stimulate bone formation and tension stimulates resorption, which is contrary to orthodontic bone remodeling. ${ }^{28}$ It is assumed that indeed PDL is this unique tissue responsible for different alveolar bone response.

In our study, we began the analysis of the effects produced by the forces at a low level: $0.1 \mathrm{~N}$. We observed that this minimum force already produces stress and strain within the periodontium and on the dental root surface. The predominant stress concentration was found in the alveolus bottom, although discreet changes occurred along the whole alveolus surface. This allows us to conclude that a force of level $0.1 \mathrm{~N}$ is already effective in terms of movement of periodontally-compromised teeth. A similar stress and strain distribution was demonstrated by Rudolph et al. and Vikram et al., but they demonstrated the results achieved by forces whose values were more than twice as high and on healthy periodontium. ${ }^{29,30}$ During orthodontic intrusion, the stress concentration occurs on a very small surface present on the alveolus bottom and the root apex. That is why it is so crucial to apply the lowest yet still effective forces. The vast majority of studies which evaluate intrusion analyze relatively higher force values acting on healthy periodontium.

Our study proved that there is a relationship between stress and strain distribution and PDL surface. The more extensive the bone defect is, the smaller the PDL surface is loaded with the same force magnitude. This is crucial in periodontally-compromised patients, in which the bone defect ranges vary between individual teeth. During treatment with fixed appliances, it is important to remember that the planned treatment biomechanics should be adjusted to the tooth with the largest bone defect; this tooth is the weakest link and thus the most susceptible to failure.

\section{Conclusions}

The bone tissue reaction to load induced by fixed orthodontic appliances and transformed by the tooth is building new internal structures, changed in terms of both their density and mechanical properties. During orthodontic treatment, the forces acting on bone tissue result in both bone formation and bone resorption. As shown in our article, the developed procedure makes possible the adequate planning of orthodontic treatment to obtain bone creation processes significantly prevailing bone resorption, which is crucial in periodontally-compromised patients. Indeed the method is based upon numerical modeling and simulation but, thanks to CT scans, the model obtained is individualized. The data obtained in such a manner allows the conclusion that a force value of $0.1 \mathrm{~N}$ applied in vivo might produce the most effective tooth intrusion and bone remodeling which favors bone defect regeneration.

\section{References}

1. Towfighi PP, Brundsvold M, Storey AT, Arnold RM, Willmand DE, McMahan CA. Pathologic migration of anterior teeth in patients with moderate to severe periodontitis. J Periodontol. 1997;68:967-972.

2. Melsen B. Tissue reaction to orthodontic tooth movement - a new paradigm. Eur J Orthod. 2001;23:671-681.

3. Romano R, Landsberg CJ. Reconstruction of function and aesthetics of the maxillary anterior region: A combined periodontal/orthodontic therapy. Pract Periodont Aesthetic Dent. 1996;8:353-361.

4. Fung K, Chandhoke TK, Uribe F, Schincaglia G. Periodontal regeneration and orthodontic intrusion of a pathologically migrated central incisor adjacent to an infrabony defect. J Clinical Orthod. 2012;7:417-423.

5. Minch L, Chrobak M, Antoszewska L. Interdisciplinary treatment of adult patients: A case report. Dent Med Probl. 2013;50:481-485.

6. Costopoulos G, Nanda R. An evaluation of root resorption incident to orthodontic intrusion. Am J Orthod Dentofac Orthop. 1996;109:543-548. 
7. Han G, Huang S, Von den Hoff J, Zeng X, Kuijpers-Jagtman AM. Root resorption after orthodontic intrusion and extrusion: An intraindividual study. Angle Orthod. 2005;75:912-918.

8. Provatidis C. A comparative fem-study of tooth mobility using isotropic and anisotropic models of the periodontal ligament. Med Eng Physics. 2000;22:359-370.

9. Jones M, Hickman J, Middleton J, Knox J, Volp C. A validated finite element method study of orthodontic tooth movement in the human subject. J Orthod. 2001;28:29-38.

10. Qian H, Chen J, Katona TR. The influence of PDL principal fibers in 3-dimensional analysis of orthodontic tooth movement. Am J Orthod Dentofac Orthop. 2001;120:272-279.

11. Cattaneo $P$, Dalstra $M$, Melsen $B$. The finite element method: A tool to study orthodontic tooth movement. J Dent Res. 2005;84:428-433.

12. Brezniak N, Wasserstein $A$. Rooth resorption after orthodontic treatment part 2. Literature review. Am J Orthod Dentofacial Orthop. 1993;103:138-146

13. Casa MA, Faltin RM, Faltin K, Sander F, Arana-Chavez VE. Rooth resorption in upper first premolars after application of continous torque moment: An intraindividual study. J Orofac Orthop. 2001;62:285-295.

14. Artun J, Van't Hullenaar R, Doppel D, Kuijpers-Jagtman AM. Identification of orthodontic patients at risk of severe apical root resorption. Am J Orthod Dentofac Orthop. 2009;135:448-455.

15. Melsen B, AgerbaekN, Eriksen J, Terp S. New attachment trough periodontal treatment and orthodontic intrusion. Am J Orthod. 1988;94:204-116.

16. Feng $X$, Oba T, Oba $Y$, Moriyama K. An interdisciplinary approach for improved functional and esthetic results in a periodontally compromised adult patient. Angle Orthod. 2005;6:1061-1070.

17. Kasai A, Wehrbein H, Gortan-Kasai A, Reichert C, Willershausen B, Cases J. Interdisciplinary approach for the treatment of periodontally compromised malpositioned anterior teeth: A case report. Cases J. 2009;2:8568.

18. Maia LG, de Moraes Maia ML, da Costa Monini A, Vianna AP, Gandini LG. Photoelastic analysis of forces generated by T-loop springs made with stainless steel or titanium-molybdenum alloy. Am J Orthod Dentofacial Orthop. 2011;140:123-128

19. Burstone CJ, Pruptyniewicz RJ. Holographic determination of centres of rotation produced by orthodontic forces. Am J Orthod. 1980;77:396-409.

20. Hinterkausen M, Bourauel C, Siebers G, Haase A, Drescher D, Nellen $B$. In vitro analysis of the initial tooth mobility in a novel optomechanical set-up. Med Engin Physics. 1998;20:40-49.

21. Cifter M, Sarac M. Maxillary posterior intrusion mechanics with mini-implant anchorage evaluated with finite element method. Am J Orthod Dentofac Orthop. 2011;140:233-241.

22. Liang W, Rong Q, Lin J, Xu B. Torque control of the maxillary incisors in lingual and labialorthodontics: A 3-dimensional finite element analysis. Am J Ortod Dentofac Orthop. 2009;135:316-322.

23. Levander $E$, Malmgren $O$. Evaluation of the risk of root resorption during orthodontic treatment. A study of upper incisors. Eur J Orthod. 1988;10:30-38.

24. Cattaneo PM, Dalstra M, Melsen B. Analysis of stress and strain around orthodontically loaded implants: An animal study. Int J Oral Maxillofacial Implants. 2007;22:213-225.

25. Cattaneo PM, Dalstra M, Melsen B. The finite element method: A too to study orthodontic movement. J Dent Res. 2005;84:428-433.

26. Poppe M, Bourauel C, Jager A. Determination of the elasticity parameters of the human periodontal ligament and the location of the center of resistance of single rooted teeth. A study of autopsy specimens and their conversion into finite element models. J Orofac Orthop. 2002;63:358-370.

27. Provatidis CG. A comparative FEM-study of tooth mobility using isotropic and anisotropic models of the periodontal ligament. Med Engin Physics. 2000;22:359-370.

28. Frost HM. Some ABC's of skeletal pathophysiology. Tissuse mechanisms controlling bone mass. Calc Tiss Int. 1991;49:303-304.

29. Rudolph DJ, Willes MG, Sameshima GT. A finite element model of apical force distribution from orthodontic tooth movement. Angle Orthod. 2001;71:127-131.

30. Vikram NR, Kumar KSS, Nagachandran KS, Hashir YM. Apical stress distribution on maxillary central incisor during various orthodontic movements by verying cementak and two different periodontal ligament thicknesses: A FEM study. Indian J Dental Res. 2012;23:213-220. 